\title{
Desempenho produtivo e econômico de novilhas Nelore suplementadas no período de transição seca-águas
}

\author{
Performance and economic evaluation of Nellore heifers \\ supplemented on the dry-rainy season transition period
}

\author{
Lilian Chambó Rondena Pesqueira-Silva ${ }^{1 *}$; Joanis Tilemahos Zervoudakis ${ }^{2}$; \\ Luciano da Silva Cabral²; Luciana Keiko Hatamoto-Zervoudakis ${ }^{2}$; \\ Renata Pereira da Silva-Marques ${ }^{1}$; Jefferson Fabiano Werner Koscheck ${ }^{3}$; \\ André Alves de Oliveira ${ }^{3}$
}

\begin{abstract}
Resumo
Objetivou-se com este experimento avaliar o ganho de peso e a viabilidade econômica de novilhas Nelore recriadas em pastagem de capim Marandu no período de transição seca-águas recebendo suplemento energético, proteico e múltiplo. Foram utilizadas vinte novilhas Nelore, com peso corporal médio inicial de $189,75 \pm 21,55 \mathrm{~kg}$ distribuídas em quatro piquetes de 1,6 ha cada. O delineamento utilizado foi inteiramente casualizado (quatro suplementos e cinco repetições) para avaliar os seguintes suplementos: suplemento energético (SE), suplemento proteico (SP) e suplemento múltiplo (SM), fornecidos na quantidade de $1 \mathrm{~kg}$ animal dia ${ }^{-1}$, além do suplemento exclusivo com mistura mineral (MM) ad libitum. A avaliação econômica foi realizada tendo em vista a remuneração do capital investido, dividindo-se a margem de lucro pelo investimento total envolvido no processo de suplementação. O ganho médio diário $(\mathrm{GMD})$ foi maior $(\mathrm{P}<0,10)$ para os animais recebendo os suplementos $\mathrm{SP}\left(0,68 \mathrm{~kg}\right.$ animal dia $\left.{ }^{-1}\right)$ e SM $\left(0,66 \mathrm{~kg}\right.$ animal dia $\left.^{-1}\right)$ em relação ao suplemento $\mathrm{MM}\left(0,48 \mathrm{~kg}\right.$ animal dia $\left.{ }^{-1}\right)$. Os resultados para ganho médio diário adicional ao suplemento MM foram de 0,088; 0,202 e 0,183 $\mathrm{kg} \mathrm{dia}^{-1}$ para os animais recebendo os suplementos SE, SP e SM, respectivamente. Em termos econômicos foi observado maior retorno para o suplemento SP $(4,38 \%)$. A utilização de suplementação protéica e múltipla promoveu maior desempenho produtivo de novilhas em pastejo suplementadas no período de transição seca-águas, entretanto o suplemento múltiplo resultou em maior viabilidade econômica.

Palavras-chave: Capim marandu, energético, múltiplo, proteico, suplementação
\end{abstract}

\begin{abstract}
The objective of this experiment was to evaluate the body weight gain and the economic viability of Nellore heifers reared on pasture grass Marandu during transition dry-waters receiving energetic, proteic and multiple supplements. Twenty Nelore heifers were used, with average initial body weight of $189.75 \pm 21.55 \mathrm{~kg}$ distributed in four paddocks of $1.6 \mathrm{ha}$ each. The experimental design was completely randomized (four supplements and five replicates) to evaluate the following supplements: energetic
\end{abstract}

\footnotetext{
${ }^{1}$ Discentes do Curso de Doutorado em Ciência Animal, Universidade Federal de Mato Grosso, UFMT, Cuiabá, MT. E-mail: lilianrondena@hotmail.com; renatinharps@hotmail.com

2 Profs., Universidade Federal de Mato Grosso, UFMT, Cuiabá, MT. E-mail: joanisz@yahoo.com.br; lucianoufmt@gmail.com; lukeiko@yahoo.com.br

3 Discentes do Curso de Doutorado em Zootecnia, Universidade Estadual Paulista, UNESP, Jaboticabal, SP. E-mail: jeffersonfwk@ hotmail.com; andrezoo07@yahoo.com.br

* Autor para correspondência
} 
supplement (ES) proteic supplement (PS) and multiple supplement (MS), provided that the amount of 1 $\mathrm{kg}$ animal day ${ }^{-1}$, beyond the exclusive supplement with mineral mixture (MM) ad libitum. The economic evaluation was conducted considering the return of invested capital by dividing the profit margin for the total investment involved in the process of supplementation. The average daily gain (ADG) was higher $(\mathrm{P}<0.10)$ for the animals receiving PS $\left(0.68 \mathrm{~kg}\right.$ animal day $\left.{ }^{-1}\right)$ and MS $\left(0.66 \mathrm{~kg}\right.$ animal day $\left.{ }^{-1}\right)$ supplements in relation to MM supplement $\left(0.48 \mathrm{~kg}\right.$ animal day $\left.{ }^{-1}\right)$. The results for average daily gain additional supplement to the MM were $0.088 ; 0.202$ and $0.183 \mathrm{~kg}$ day for animals receiving the ES, PS and MS supplements, respectively. In economic terms was observed higher return for the PS supplement $(4.38 \%)$. The use of proteic supplementation and multiple promoted more productive performance of heifers supplemented grazing in the transition dry-waters, however the multiple supplement resulted in greater economic viability.

Key words: Energetic, grass marandu, multiple, proteic, supplementation

\section{Introdução}

A produção de bovinos nos trópicos tem como base o uso de forragem com animais mantidos em pastejo, o que torna o sistema produtivo com excelente competitividade, em função do baixo custo de produção em relação a outros países, uma vez que o próprio animal colhe a forragem, diferentemente do que é necessário nos confinamentos americanos e europeus.

Apesar da competitividade, a produção de bovinos em pastagens enfrenta sérios desafios, uma vez que devido à distribuição desuniforme das chuvas ao longo do ano, resulta em acentuada variação na qualidade e quantidade de forragem disponível ao animal para atender seus requerimentos nutricionais. Dessa forma, o ganho médio diário de animais em pastagens mostra padrão sazonal, com valores satisfatórios ( $650 \mathrm{~g}$ animal $\left.\mathrm{dia}^{-1}\right)$ no período das chuvas, outubro a abril, e negativos no período seco do ano, maio a setembro (PRADO et al., 2003; MOREIRA et al., 2004), o que permite afirmar de acordo com Silva et al. (2009) que forragens tropicais são capazes de produzir adequado desempenho dos animais por período de tempo relativamente limitado.

Sendo assim, uma alternativa para aumentar a capacidade de suporte das pastagens e o ganho de peso dos animais mantidos sob pastejo consiste no manejo estratégico da pastagem por meio da adubação, pastejo diferido e adequação da taxa de lotação (CECATO et al., 2004; CECATO et al., 2008). Além dessas estratégias de manejo, a associação da suplementação alimentar dos animais é essencial para possibilitar níveis adequados de desempenho, uma vez que gramíneas tropicais podem apresentar adequada disponibilidade de forragem com baixo valor nutritivo (REIS et al. 2009). Neste contexto, Zervoudakis et al. (2010) relataram que quando se objetiva promover durante a fase de recria, crescimento contínuo dos animais e a competitividade da atividade, é necessário lançar mão da suplementação estratégica, não só no período seco do ano, pois com isso permite-se diluir os custos fixos pelo aumento na taxa de lotação das pastagens, redução no tempo para o abate e idade ao primeiro parto e, consequentemente, maior produtividade de sistemas de produção de carne a pasto.

Com base no exposto, objetivou-se avaliar o fornecimento de suplemento energético, protéico e múltiplo sobre o ganho de peso e viabilidade econômica na recria de novilhas sob pastejo em capim Marandu no período de transição seca-águas.

\section{Material e Métodos}

O experimento foi conduzido no Setor de Bovinocultura de Corte da Fazenda Experimental da Faculdade de Agronomia, Medicina Veterinária e Zootecnia da Universidade Federal de Mato Grosso, localizada no município de Santo Antônio do Leverger - MT, durante o período de transição 
seca-águas, entre os meses de agosto a outubro de 2010 .

Foram utilizadas 20 novilhas da raça Nelore com peso corporal (PC) médio inicial de 189,75 $\pm 21,56$ $\mathrm{kg}$ e idade média de 12 meses. A área experimental destinada aos animais foi constituída de quatro piquetes de 1,6 ha cada, formados uniformemente com Brachiaria brizantha cv. Marandu.

O experimento foi conduzido em três períodos experimentais de 28 dias cada, perfazendo um total de 84 dias, onde foram avaliados quatro suplementos, sendo: $\mathrm{MM}=$ mistura mineral (testemunha); $\mathrm{SE}=$ suplemento energético; $\mathrm{SP}=$ suplemento proteico e $\mathrm{SM}=$ suplemento múltiplo (Tabela 1 ), fornecidos na quantidade de $1 \mathrm{~kg}$ animal dia ${ }^{-1}$ na matéria natural, às $10 \mathrm{~h} 00$ da manhã.

As novilhas foram pesadas a cada 28 dias. A pesagem inicial e pesagem final foram precedidas de jejum de sólidos de 14 horas, nas pesagens intermediárias não houve jejum prévio. Visando minimizar a influência da possível variação na massa de forragem (MF) entre os piquetes foi realizado o rodízio dos animais nestes a cada 14 dias.

Tabela 1. Composição $\mathrm{g} / \mathrm{kg}$ e custo em reais (R\$) do suplemento mistura mineral (MM), suplemento energético (SE), suplemento proteico (SP) e suplemento múltiplo (SM) com base na matéria seca.

\begin{tabular}{lccccc}
\hline \multirow{2}{*}{ Ingrediente } & \multicolumn{4}{c}{ Suplemento } & \multirow{2}{*}{ Custo (R\$/kg) } \\
\cline { 2 - 5 } & $\mathrm{MM}$ & $\mathrm{SE}$ & $\mathrm{SP}$ & $\mathrm{SM}$ & \\
\hline Farelo de soja & - & 8 & 82 & 46 & 0,56 \\
Milho grão moído & - & 84 & 10 & 46 & 0,44 \\
Ureia & - & 1,8 & 1,8 & 1,8 & 1,92 \\
Sulfato de amônio & & 0,2 & 0,2 & 0,2 & 1,26 \\
Mistura mineral completa & 100 & 6 & 6 & 6 & 1,17 \\
\hline
\end{tabular}

Fonte: Elaboração dos autores.

No primeiro dia de cada período experimental realizou-se a coleta de amostras da forragem nos diferentes piquetes. Para esta amostragem foram realizadas medições da altura da forragem em 100 pontos por piquete, divididos em duas diagonais (50 pontos por diagonal). Após a medição os valores foram somados para confecção de uma altura media da forragem por piquete e coletada a forragem a $5 \mathrm{~cm}$ do solo com um quadrado metálico de $1 \mathrm{~m}^{2}$ em um ponto do piquete que cuja altura fosse igual a media obtida pela medição. Após a pesagem, foi feita homogeneização das amostras por piquete e dessas retiradas duas amostras compostas, uma para determinação da massa de forragem (MF) e outra para determinação do percentual das frações folha verde, folha seca, colmo verde e colmo seco. Para a avaliação da forragem ingerida pelos animais foi utilizada a técnica da simulação manual de pastejo.

Das amostras destinadas à estimativa da MF, foi calculado o percentual de matéria seca potencialmente digestível (MSpD) segundo Paulino et al. (2004), por intermédio da fibra insolúvel em detergente neutro indigerível (FDNi) obtido após incubação in situ das amostras por 240 horas em sacos de tecido não tecido (TNT - 100g/ $\mathrm{m}^{2}$ ) em triplicata $\left(20 \mathrm{mg}\right.$ de matéria $\left.\mathrm{seca} / \mathrm{cm}^{2}\right)$, segundo Casali et al. (2008).

Amostras de ingredientes, suplementos e forragem (simulação do pastejo) foram analisadas para determinação da matéria seca (MS), matéria mineral(MM), matéria orgânica(MO), proteína bruta (PB), extrato etéreo (EE) e fibra em detergente ácido (FDA) de acordo com os métodos da Association 
of Official Analytical Chemists (AOAC, 1990). Os teores de fibra em detergente neutro (FDN) foram determinadas utilizando-se sacos de tecido não tecido (TNT - $100 \mathrm{~g} / \mathrm{m}^{2}$ ), 100\% polipropileno, contendo $20 \mathrm{mg}$ de $\mathrm{MS} / \mathrm{cm}^{2}$, mergulhados em solução detergente neutra contendo alfa amilase termoestável (VAN SOEST; ROBERTSON; LEWIS, 1991), submetidos a autoclave a $105^{\circ} \mathrm{C}$ por uma hora (PELL; SCHOFIELD, 1993). Os resíduos da FDN foram corrigidos para cinzas e proteína seguindo as recomendações de Licitra, Hernandez e Van Soest (1996) e Mertens (2002).

A determinação do nitrogênio insolúvel em solução detergente neutra (NIDN) e ácida (NIDA) foram realizadas conforme técnicas propostas por Van Soest, Robertson e Lewis (1991).

A quantificação dos carboidratos totais (CT) foi obtida pela equação proposta por Sniffen et al. (1992). Os carboidratos não fibrosos (CNF) dos suplementos foram estimados de acordo com adaptação de Hall e Akinyode (2000), em função da inclusão da ureia na composição dos suplementos. Os teores de nutrientes digestíveis totais (NDT) foram estimados segundo o NRC (2001).

A avaliação econômica foi realizada tendo em vista a remuneração do capital investido, dividindo-se a margem de lucro pelo investimento total envolvido no processo de suplementação, considerando rendimento de carcaça de $52 \%$.

A receita foi obtida pela multiplicação do ganho em equivalente carcaça pelo valor da arroba na região ( $\mathrm{R} \$ 82,36)$ e as despesas foram obtidas pelo custo total com pasto $(15 \%$ do valor médio da@ mais o custo operacional e custos com sanidade, mão-de-obra entre outros (R\$ 0,128/ dia)), custo com suplemento (considerando o valor do quilograma dos suplementos) e custo com os animais com atualização do início até o fim do período experimental em relação à taxa de juros (Preço da novilha aos 12 meses de idade sob a taxa de juros $(0,6 \% /$ mês $)$. Todas as cotações empregadas foram tomadas no ano de 2012 e na região em que se conduziu este experimento.

As análises referentes ao desempenho dos animais foram conduzidas considerando delineamento inteiramente casualizado com quatro suplementos e cinco repetições. Os resultados foram interpretados estatisticamente por meio de análises de variância. Para as comparações dos suplementos adotouse o teste de médias Students-Newman-Keulls (SNK), por meio do procedimento GLM do sistema estatístico Statistical Analysis System, versão 9.1.3, a 10\% de significância.

\section{Resultados e Discussão}

A média de massa de forragem observada no pasto de capim Marandu durante o experimento foi de 2769,33 kg (Figura 1), valor este abaixo do valor mínimo de $4.500 \mathrm{~kg}$ de MS total ha-1 preconizados por Silva et al. (2009) para garantir seletividade e ganhos individuais satisfatórios sem comprometer o ganho por área.

Reis et al. (2009) relataram que mesmo quando a massa de forragem é adequada existem outras características da gramínea forrageira que se tornam importantes, uma vez que a seleção da dieta é função da seletividade do animal por partes especificas da planta (folhas verdes), consequentemente, o consumo máximo ocorre quando o animal tem a sua disposição forragem com adequada densidade de folhas.

Desta forma, Paulino et al. (2004) relataram que a interpretação da oferta de forragem disponível animal deve ser feita sob a ótica da fração potencialmente convertível em produto, alcançado pela utilização da oferta de MSpD (kg para cada $100 \mathrm{~kg}$ de peso corporal (PC) por animal dia), que envolve a estrutura do pasto (massa de forragem, altura do pasto, razão folha:colmo) e qualidade do pasto em todas as épocas do ano, sendo os valores indicados de 4,0 a 5,0 $\mathrm{kg}$ para cada $100 \mathrm{~kg}$ de $\mathrm{PC}$ por animal dia $^{-1}$, visando associar produção por animal, por área e eficiência de pastejo. 
Figura 1. Valores médios para a massa de forragem (MF), matéria seca potencialmente digestível (MSpD), massa seca de folha verde (MSFV), massa seca de folha seca (MSFS), massa seca de colmo verde (MSCV) e massa seca de colmo seco (MSCS) nos meses experimentais.

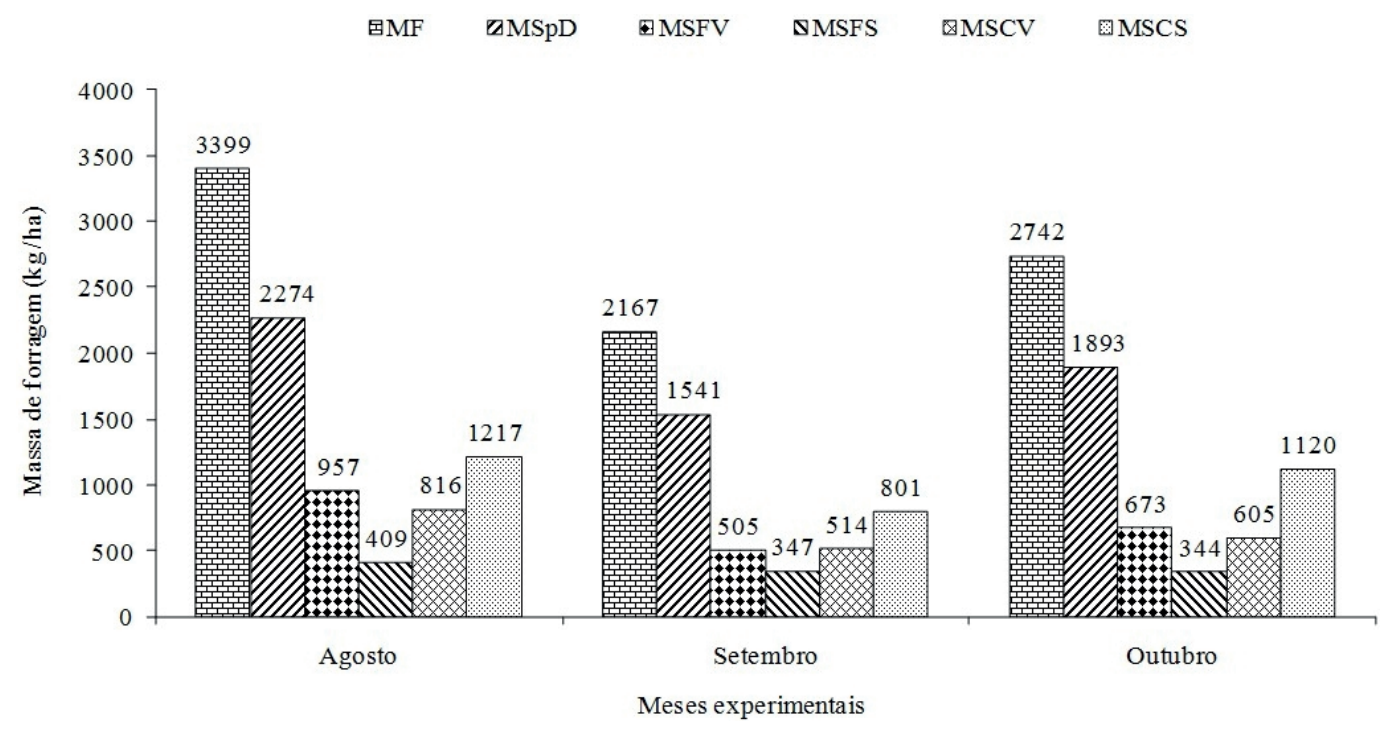

Fonte: Elaboração dos autores.

No presente estudo, a disponibilidade média de MSpD foi correspondente a 69,02\% da MF, o que propiciou uma oferta média de $\mathrm{MSpD}$ de $10 \mathrm{~kg}$ para cada $100 \mathrm{~kg}$ de PC animal dia $^{-1}$
(Figura2). Pode-se inferir por esses resultados que esses valores permitiram a seletividade animal e, consequentemente, proporcionaram efeito positivo no desempenho dos animais.

Figura 2. Valores médios para a oferta ( $\mathrm{kg} \mathrm{MS} / 100 \mathrm{~kg}$ de PC) de massa de forragem (MF), matéria seca potencialmente digestível (MSpD), massa seca de folha verde (MFV), massa seca de folha seca (MFS), massa seca de colmo verde $(\mathrm{MCV})$ e massa seca de colmo seco (MCS) nos meses experimentais.

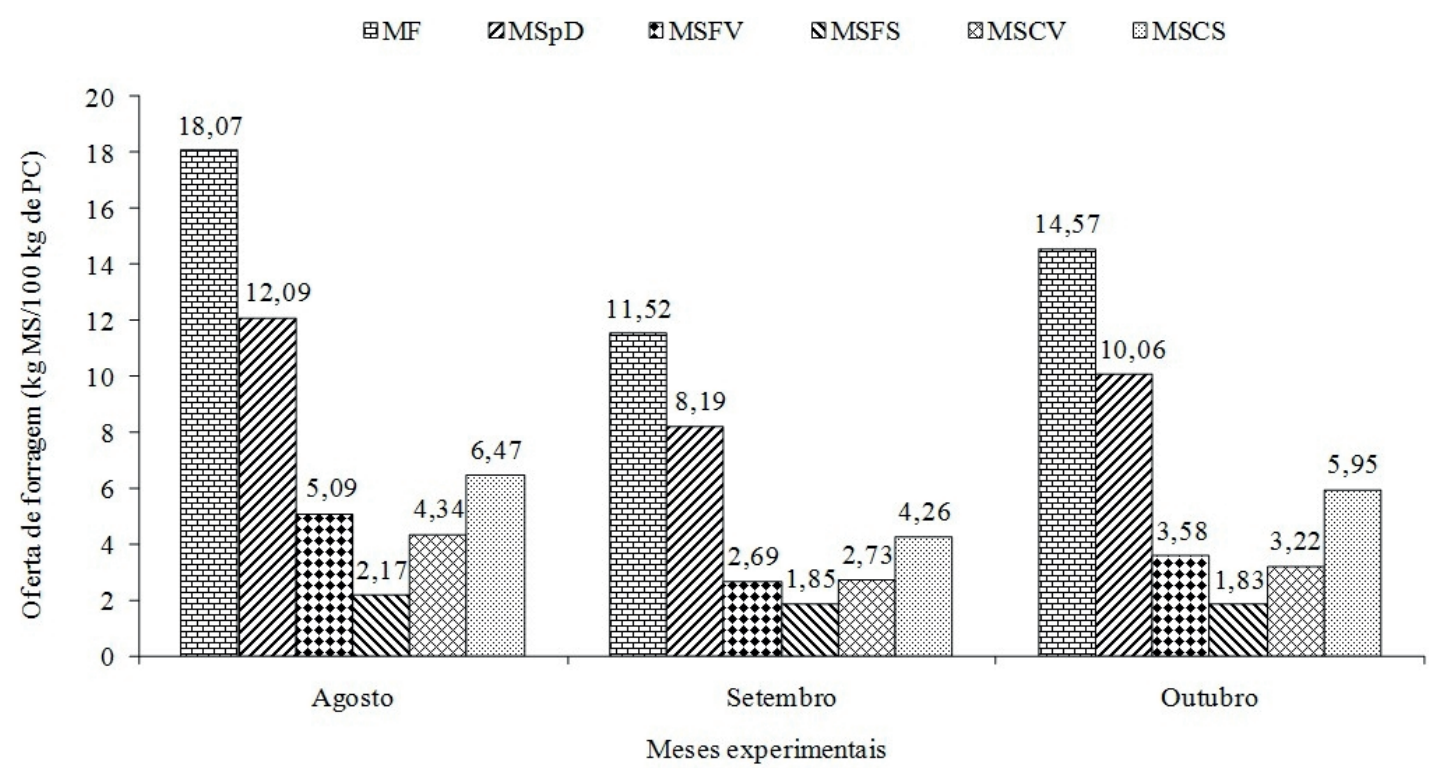

Fonte: Elaboração dos autores. 
O teor médio de proteína bruta (PB) na forragem obtida via simulação manual do pastejo foi de $6,45 \%$ (Tabela 2), valor abaixo de 7,0\% de $\mathrm{PB}$ na dieta basal, considerado como nível crítico para satisfazer as exigências microbianas em compostos nitrogenados e permitir a fermentação dos carboidratos fibrosos no rúmen (LAZZARINI et al., 2009).

Tabela 2. Composição bromatológica da forragem obtida via simulação manual do pastejo e do suplemento energético (SE), proteico (SP) e múltiplo (SM) com base na matéria seca.

\begin{tabular}{lrrrc}
\hline \multirow{2}{*}{\multicolumn{1}{c}{ Item $^{*}$}} & \multicolumn{3}{c}{ Suplemento } & \multirow{2}{*}{ B. Brizantha } \\
\cline { 2 - 4 } & SE & SP & SM & 37,01 \\
Matéria seca $^{1}$ & 91,91 & 92,58 & 90,96 & 10,57 \\
Matéria mineral $^{2}$ & 7,53 & 9,64 & 10,81 & 89,43 \\
Matéria orgânica $^{2}$ & 92,47 & 90,36 & 89,19 & 6,45 \\
Proteína bruta $^{2}$ & 17,91 & 47,59 & 35,69 & 2,18 \\
Extrato etéreo $^{2}$ & 2,28 & 1,82 & 1,27 & 80,80 \\
Carboidratos totais $^{2}$ & 72,27 & 40,95 & 52,23 & 69,88 \\
Fibra insolúvel em detergente neutro (FDN) $^{2}$ & 11,51 & 13,21 & 11,24 & 35,80 \\
Fibra insolúvel em detergente ácido $^{2}$ & 2,92 & 4,66 & 3,11 & 62,34 \\
FDN corrigida cinzas e proteína $^{3}$ & 10,86 & 12,50 & 10,59 & 18,46 \\
Carboidratos não fibrosos $^{2}$ & 64,67 & 31,71 & 44,91 & 22,66 \\
FDN indigerível $^{2}$ & 2,51 & 3,26 & 3,59 & 36,48 \\
Nitrogênio insolúvel em detergente neutro $^{3}$ & 2,95 & 1,22 & 1,47 & 11,94 \\
Nitrogênio insolúvel em detergente ácido $^{3}$ & 2,14 & 2,55 & 3,53 & 52,38 \\
Nutrientes digestíveis totais $^{2,4}$ & 82,11 & 79,02 & 77,29 & \\
\hline
\end{tabular}

${ }^{1}(\%$ matéria natural $) ;{ }^{2}$ (\% matéria seca $) ;{ }^{3}$ (\% nitrogênio total $) ;{ }^{4}$ Estimado segundo NRC (2001).

Fonte: Elaboração dos autores.

Pode-se constatar teores de fibra insolúvel em detergente neutro (FDN) e fibra insolúvel em detergente neutro indigerível (FDNi) de 69,88 e $22,66 \%$, respectivamente, que implicaria em redução no conteúdo celular e redução nos teores de nitrogênio. Entretanto, o teor de nitrogênio insolúvel em detergente ácido (NIDA) foi de $11,94 \%$ do N total.

É conhecido que o valor nutritivo da gramínea forrageira tropical é reduzido com o avançar da idade fisiológica da planta, uma vez que a mesma apresenta alterações morfofisiológicas que resultam no aumento de colmos e redução na proporção de folhas, ocorre lignificação da parede celular, reduzindo a proporção do conteúdo celular, principalmente nos colmos (Van Soest, 1994), denotando a necessidade de correções no balanço de nutrientes em dietas de animais sob pastejo pela suplementação.

Pode-se verificar que as novilhas que receberam o suplemento SP e SM obtiveram GMD superior $(\mathrm{P}<0,10)$ aos observados para os animais recebendo apenas MM (Tabela 3). Os resultados para ganho médio diário adicional ao suplemento $\mathrm{MM}$ foram de 0,$088 ; 0,202$ e $0,183 \mathrm{~kg} \mathrm{dia}^{-1}$ para os animais recebendo os suplementos SE, SP e SM, respectivamente.

O maior desempenho para as novilhas recebendo SP e SM pode ser atribuído ao maior consumo de compostos nitrogenados, propiciando assim melhor uso da forragem consumida pelos animais, uma vez que os suplementos SP e SM possuíam 47,59 e $35,69 \%$ de $\mathrm{PB}$, enquanto o SE continha $17,91 \%$ de PB. 
Moraes et al. (2006) avaliando níveis de proteína (8, 16 e $24 \%$ de PB) em suplementos no período de transição seca-águas, verificaram aumento linear no desempenho produtivo dos animais com o aumento no teor de proteína bruta dos suplementos.

Tabela 3. Peso corporal inicial (PCi), peso corporal final (PCf), ganho de peso total (GPT), ganho médio diário (GMD) e ganho médio diário adicional (GMDA) de novilhas em pastejo recebendo suplementação mineral (MM), energética (SE), proteica (SP) e múltipla (SM) no período de transição seca-águas.

\begin{tabular}{lcccc}
\hline \multirow{2}{*}{ Variável } & \multicolumn{4}{c}{ Suplemento } \\
\cline { 2 - 5 } & MM & SE & SP & SM \\
\hline PCi $(\mathrm{kg})$ & $189,20 \pm 15,79$ & $190,00 \pm 32,13$ & $190,00 \pm 24,24$ & $189,80 \pm 18,39$ \\
PCf $(\mathrm{kg})$ & $229,60 \pm 15,79$ & $237,80 \pm 32,13$ & $247,40 \pm 32,13$ & $245,60 \pm 32,13$ \\
GPT $(\mathrm{kg})$ & $40,40 \pm 9,13$ & $47,80 \pm 6,38$ & $57,40 \pm 16,65$ & $55,80 \pm 10,40$ \\
GMD $(\mathrm{kg})$ & $0,481 \pm 0,109^{\mathrm{b}}$ & $0,569 \pm 0,076^{\mathrm{ab}}$ & $0,683 \pm 0,114^{\mathrm{a}}$ & $0,664 \pm 0,124^{\mathrm{a}}$ \\
GMDA $(\mathrm{kg})$ & - & 0,088 & 0,202 & 0,183 \\
\hline
\end{tabular}

Valores seguidos de letras iguais na linha, não diferem pelo teste SNK a 0,10 de probabilidade.

Fonte: Elaboração dos autores.

$\mathrm{O}$ adequado desempenho alcançado pelos os animais recebendo apenas MM pode ser explicado, provavelmente devido à alta pluviosidade durante o período experimental. Dessa forma, esse fato permitiu a alta oferta de MSpD (Figura 2), proporcionando aos animais seletividade ao pastejar.

Com relação aos índices econômicos pode-se verificar que os investimentos mais elevados de suplemento foram para os suplementos SP e SM, e isso é reflexo da inclusão de farelo de soja como principal ingrediente proteico dos suplementos (Tabela 4). Confirmando esses dados podese verificar que o SP teve o seu custo unitário aumentado em R\$ 3,36 e R\$ 7,56 em relação aos suplementos SM e SE, respectivamente.

Tabela 4. Indicadores econômicos de produção animal para novilhas recebendo mistura mineral (MM), suplemento energético (SE), suplemento proteico (SP) e suplemento múltiplo (SM).

Continua $\ldots$

\begin{tabular}{lcccc}
\hline \multirow{2}{*}{\multicolumn{1}{c}{ Item }} & \multicolumn{4}{c}{ Suplemento } \\
\cline { 2 - 4 } & MM & SE & SP & SM \\
\hline Peso corporal inicial $(\mathrm{kg})$ & 189,20 & 190,00 & 190,00 & 189,80 \\
Ganho de peso médio diário (kg/dia) & 0,481 & 0,569 & 0,683 & 0,664 \\
Ganho de peso total (kg) & 40,40 & 47,80 & 57,40 & 55,80 \\
Peso corporal final & 229,60 & 237,80 & 247,40 & 245,60 \\
Duração do período experimental (mês) & 2,80 & 2,80 & 2,80 & 2,80 \\
Idade ao abate (meses) & 14,80 & 14,80 & 14,80 & 14,80 \\
Consumo de suplemento (kg/dia) & 0,07 & 1,00 & 1,00 & 1,00 \\
Custo do suplemento $(\mathrm{R} \$ / \mathrm{kg})$ & 1,17 & 0,52 & 0,61 & 0,57 \\
Investimento com suplemento $(\mathrm{R} \$)^{1}$ & 6,58 & 43,68 & 51,24 & 47,88 \\
Investimento com pasto $(\mathrm{R} \$)^{2}$ & 45,02 & 45,02 & 45,02 & 45,02 \\
Atualização do preço novilha $(\mathrm{R} \$)^{3}$ & 532,85 & 532,85 & 532,85 & 532,85 \\
\hline
\end{tabular}




\begin{tabular}{lcccc} 
& \multicolumn{3}{c}{.. Continuação } \\
\hline Investimento total $(\mathrm{R} \$)^{4}$ & 584,46 & 621,55 & 629,11 & 625,75 \\
Receita $(\mathrm{R} \$)^{5}$ & 655,53 & 678,94 & 706,36 & 701,23 \\
Lucro $(\mathrm{R} \$)^{6}$ & 71,07 & 57,39 & 77,24 & 75,47 \\
Remuneração capital investido período $(\%)^{7}$ & 12,16 & 9,23 & 12,28 & 12,06 \\
Remuneração mensal do capital investido $(\%)^{8}$ & 4,34 & 3,30 & 4,38 & 4,31 \\
\hline
\end{tabular}

${ }^{1}$ Consumo suplemento*duração ciclo (meses)*30 dias*Custo suplemento; ${ }^{2} 15 \%$ do valor médio da @ durante o período experimental + Custo operacional e outros custos $\left(=15 \% * 81,59+(0,128 * 84\right.$ dias de experimento $) ;{ }^{3}$ Preço novilha aos 12 meses $(\mathrm{R} \$$ $524,00) *\left[1+(0,6 \% \text { taxa de juros/100) }]^{\wedge}\right.$ duração período experimental; ${ }^{4}$ Investimento pasto + investimento suplemento + atualização preço da novilha; ${ }^{5}$ Venda novilhas considerado 52\% de rendimento de carcaça *valor da @ de R\$ 82,36; ${ }^{6}$ Receita -Investimento total; ${ }^{7}$ Lucro/Investimento total ${ }^{*} 100 ;{ }^{8}$ (Lucro/Investimento total*100)/2,8 meses)).

Fonte: Elaboração dos autores.

Apesar do elevado investimento com o suplemento SP, esta estratégia proporcionou numericamente aos animais atingirem maior GMD, maior receita e maior remuneração sobre o capital investido durante o período experimental.

A elevada remuneração obtida com o suplemento mistura mineral pode ser justificada pelo fato deste tipo de suplemento ser de baixo consumo, o que resulta em baixo investimento com o suplemento, além disso, o uso de apenas mistura mineral nas condições deste estudo resultou em elevado GMD o que impossibilitou maiores ganhos adicionais aos animais recebendo às demais estratégias de suplementação (Tabela 5). Desta forma, quando os índices são apresentados considerando o peso corporal adicional em relação ao suplemento MM, pode-se verificar que todos os suplementos concentrados apresentaram retorno relativo negativo, uma vez que, os ganhos adicionais diários obtidos não foram capazes de abonar os custos diários da suplementação.

Tabela 5. Indicadores econômicos de produção animal para cada estratégia de suplementação, em função do peso corporal adicional.

\begin{tabular}{|c|c|c|c|}
\hline \multirow{2}{*}{ Item } & \multicolumn{3}{|c|}{ Suplemento } \\
\hline & SE & SP & SM \\
\hline Custos da suplementação (R $\$$ /84 dias) & 43,68 & 51,24 & 47,88 \\
\hline Peso corporal adicional (PCA) $(\mathrm{kg} / \mathrm{dia})^{1}$ & 0,09 & 0,20 & 0,18 \\
\hline Receita $(\mathrm{RC})$ por $\mathrm{kg}$ de $\mathrm{PCA}(\mathrm{R} \$)^{2}$ & 2,86 & 2,86 & 2,86 \\
\hline Receita do PCA em 84 dias $(\mathrm{R} \$)^{3}$ & 21,13 & 48,54 & 43,91 \\
\hline Resposta produtiva (RP) $(\mathrm{kg} / \mathrm{kg})^{4}$ & 0,08 & 0,20 & 0,18 \\
\hline Preço máximo do suplemento (PMS) $(\mathrm{R} \$)^{5}$ & 0,25 & 0,58 & 0,52 \\
\hline Custo suplementação/animal/dia $(\mathrm{R} \$)^{6}$ & 0,25 & 0,58 & 0,52 \\
\hline Retorno relativo $(\mathrm{R} \$)^{7}$ & 0,48 & 0,95 & 0,92 \\
\hline
\end{tabular}

${ }^{1}$ Ganho diferencial em relação aos animais suplementados com mistura mineral; ${ }^{2} \mathrm{RC}=$ (preço da @ $\left.(\mathrm{R} \$ 82,36) / 15 \mathrm{~kg}\right) * 0,52$ (rendimento carcaça); ${ }^{3} \mathrm{Receita}=(\mathrm{RC} * \mathrm{PCA} * 84$ dias $) ;{ }^{4} \mathrm{RP}=\mathrm{PCA} /$ consumo de suplemento; ${ }^{5} \mathrm{PMS}=\mathrm{RC} * \mathrm{RP} ;{ }^{6}(\mathrm{Consumo}$ de suplemento*PMS); ${ }^{7}$ Receita do PCA/custos da suplementação.

Fonte: Elaboração dos autores.

Silva et al. (2010) verificaram que a utilização (controle, 0,3; 0,6 e 0,9\% do peso vivo do animal) de níveis de suplementação com concentrado em comparação à suplementação com sal mineral, 
apesar de ter aumentado os ganhos médios adicionais (107, 142 e $240 \mathrm{~g} \mathrm{dia}^{-1}$ respectivamente), estes não foram suficientes para viabilizar economicamente a suplementação no nível de 0,6 e $0,9 \%$ do peso vivo do animal, uma vez que os custos de produção também incrementaram. Portanto, mesmo proporcionando o menor ganho adicional, o nível de suplementação até $0,3 \%$ do peso vivo foi o que resultou em viabilidade e potencial econômico.

Ganhos de peso adicionais de 180 a $200 \mathrm{~g} \mathrm{dia}^{-1}$ para bovinos a pasto no período de transição secaáguas podem parecer pouco vantajosos, porém para um sistema produtivo de ciclo curto, que visa o abate de animais com menos de 30 meses de idade pode ser muito vantajoso (PAULINO et al., 2004).

Sendo assim, optou-se por interpretar os indicadores econômicos sobre a projeção de dias para atingir $405 \mathrm{~kg}$ de peso corporal, o que permitiu avaliar as despesas totais com insumos e o benefício gerado pela antecipação na liberação da pastagem (Tabela 6).

Para a simulação, adotaram-se todos os indicadores usados na Tabela 4 e 5 ressalvando a pressuposição de que os animais provenientes do suplemento SE, SP e SM apresentariam GMD de 0,$81 ; 0,71 ; 0,51$ e $0,57 \mathrm{~kg} \mathrm{dia}^{-1}$ durante os períodos das águas, águas/seca, seca e seca/águas do ano, respectivamente. Já os animais recebendo MM apresentariam GMD de 0,64; 0,47;0,18 e $0,43 \mathrm{~kg} \mathrm{dia}^{-1}$, respectivamente. Apesar de animais recebendo apenas mistura mineral poder apresentar desempenho negativo no período seco do ano, ressalta-se que todos os valores de GMD foram obtidos por meio de compilação de dados (107 experimentos). Esse resultado justifica-se pelo fato de animais provenientes de um período de seca sem suplementação apresentarem no período das águas subsequente ganho compensatório.

Tabela 6. Indicadores econômicos de produção animal para cada estratégia de suplementação, em função do total necessário em suplementação e ocupação de pastagem para o alcance de $405 \mathrm{~kg}$ de peso corporal (PC).

\begin{tabular}{lcccc}
\hline \multirow{2}{*}{\multicolumn{1}{c}{ Item }} & \multicolumn{4}{c}{ Suplemento } \\
\cline { 2 - 5 } & MM & SE & SP & SM \\
\hline Duração do ciclo (meses) para 405 kg de PC & 15,87 & 13,77 & 10,14 & 10,26 \\
Idade ao abate (meses) & 27,87 & 25,77 & 22,14 & 22,26 \\
Investimento com suplemento (R\$) & 30,74 & 171,13 & 134,32 & 127,57 \\
Investimento com pasto (R\$) & 211,60 & 177,60 & 118,83 & 120,78 \\
Atualização do preço novilha (R\$) & 708,84 & 724,99 & 738,07 & 733,23 \\
Investimento total (R\$) & 951,18 & 1073,73 & 991,22 & 981,58 \\
Receita (R\$) & 1156,33 & 1156,33 & 1156,33 & 1156,33 \\
Lucro (R\$) & 205,15 & 82,61 & 165,11 & 174,76 \\
Ganho com desocupação de pastagem (R\$) & -- & 25,94 & 70,77 & 69,28 \\
Lucro final (R\$) & 205,15 & 108,54 & 235,88 & 244,04 \\
Remuneração capital investido período (\%) & 21,57 & 10,11 & 23,80 & 24,86 \\
Remuneração mensal capital investido (\%) & 1,65 & 0,92 & 3,24 & 3,33 \\
\hline
\end{tabular}

${ }^{1} 15 \%$ do valor da @ (R \$ 82,36)*período de desocupação em relação ao grupo controle; ${ }^{2}$ Lucro + Ganho com desocupação de pastagem; ${ }^{3}$ Lucro/Investimento total*100; ${ }^{4}$ (Lucro/Investimento total*100)/duração do ciclo)).

Fonte: Elaboração dos autores.

Pela simulação pode-se constatar que os animais que receberam o suplemento $\mathrm{MM}$ necessitam de
2,$10 ; 5,73$ e 5,61 meses a mais que os suplementos SE, SP e SM, respectivamente, para atingir os 405 
$\mathrm{kg}$ de peso corporal, o que proporciona um custo adicional com pastagens em relação aos animais recebendo suplementos SE, SP e SM de R\$ 34,00; 92,77 e 90,82, respectivamente (Tabela 6).

Os suplementos SP e SM proporcionaram maior retorno sob o capital investido resultado este em função da redução da idade de abate dos animais $(22,14$ e 22,26 meses, respectivamente) em relação aos recebendo apenas MM (27,87 meses) e do benefício da desocupação de pastagens apontando ser este o grande diferencial sobre a decisão de adotar sistema de suplementação a pasto, corroborando os resultados encontrados por Detmann et al. (2004).

O suplemento SE, devido ao baixo desempenho produtivo proporcionado as novilhas e o custo com o suplemento, resultou em remuneração mensal negativa sobre o capital investido. Dessa forma, pode-se afirmar que o fornecimento de suplemento múltiplo no período de transição seca-águas apresentou maior retorno econômico em relação ao SP e SE, com redução de custos e elevação no resultado econômico da suplementação neste período.

Adicionalmente, cabe ressaltar que a lucratividade do sistema de produção é altamente dependente das variações de mercado, tanto para preços de aquisição de insumos quanto para venda de animais, sendo assim, menores cotações podem elevar de forma satisfatória a lucratividade do sistema.

\section{Conclusões}

O fornecimento de suplemento proteico e múltiplo resultam em maior desempenho produtivo de bovinos em pastejo no período de transição seca-águas. A utilização do suplemento múltiplo proporciona maior rentabilidade para a recria de novilhas durante o período de transição seca-águas.

\section{Referências}

ASSOCIATION OF OFFICIAL ANALYTICAL CHEMISTS. Official methods of analysis. 15. ed. Arlington: AOAC, 1990. 1117 p.

CASALI, A. O.; DETMANN, E.; VALADARES FILHO, S. C.; PEREIRA, J. C.; HENRIQUES, L. T.; FREITAS, S. G.; PAULINO, M. F. Influência do tempo de incubação e do tamanho de partículas sobre os teores de compostos indigestíveis em alimentos e fezes bovina obtidos por procedimentos in situ. Revista Brasileira de Zootecnia, Viçosa, MG, v. 37, n. 2, p. 335-342, 2008.

CECATO, U.; PEREIRA, L. A. F.; GALBEIRO, S.; SANTOS, G. T.; DAMASCENO, J. C.; MACHADO, A. O. Influência da adubação nitrogenada e fosfatada sobre a produção e características da rebrota do capim Marandu (Brachiaria brizantha (Hochst) Stapf cv. Marandu. Acta Scientiarum Animal Science, Maringá, v. 26, n. 3, p. 399407, 2004.

CECATO, U.; SKROBOT, V. D.; FAKIR, G. B.; BRANCO, A. F.; GALBEIRO, S.; GOMES, J. A. N. Perfilhamento e características estruturais do capimMombaça, adubado com fontes de fósforo, em pastejo. Acta Scientiarum Animal Science, Maringá, v. 30, n. 1, p. 1-7, 2008.

DETMANN, E.; PAULINO, M. F.; ZERVOUDALIS, J. T.; CECON, P. R.; VALADARES FILHO, S. C.; GONÇALVES, L. C.; CABRAL, L. S.; MELO, A. J. N. Níveis de proteína bruta em suplementos múltiplos para terminação de novilhos mestiços em pastejo durante a época seca: desempenho produtivo e características de carcaça. Revista Brasileira de Zootecnia, Viçosa, MG, v. 33, n. 1, p. 169-180, 2004.

HALL, M. B.; AKINYODE, A. Cottonseed hulls:working with a novel fiber source. In: ANNUAL FLORIDA RUMINANT NUTRITION SYMPOSIUM, 11., 2000, Gainesville. Proceedings... Gainesville:University of Florida, 2000. p. 179-186.

LAZZARINI, I.; DETMANN, E.; SAMPAIO. C. B.; PAULINO, M. F.; VALADARES FILHO, S. C.; SOUZA, M. A.; OLIVEIRA, F. A. Intake and digestibility in cattle fed low-quality tropical forage and supplemented with nitrogenous compounds. Revista Brasileira de Zootecnia, Viçosa, MG, v. 38, n. 10, p. 2021-2030, 2009.

LICITRA, G.; HERNANDEZ, T. M.; VAN SOEST, P. J. Standardization of procedures for nitrogen fractionation of ruminant feeds. Animal Feed Science Technology. Morrison Hall, Ithaca, v. 57, n. 4, p. 347-358, 1996.

MERTENS, D. R. Gravimetric determination of amylasetreated neutral detergente fiber in feeds with refluxing 
in beakers or crucibles: Collaborative study. Journal of AOAC International, Madson, v. 85, n. 6, p. 1217-1240, 2002.

MORAES, E. H. B. K.; PAULINO, M. F.; ZERVOUDAKIS, J. T.; DETMANN, E.; VALADARES FILHO, S. C.; VALADARES, R. F. D.; MORAES, K. A. K. Níveis de proteína em suplementos para novilhos mestiços em pastejo durante o período de transição seca/ águas. Revista Brasileira de Zootecnia, Viçosa, MG, v. 35, n. 5, p. 2135-2143, 2006.

MOREIRA, F. B.; PRADO, I. N.; CECATO, U.; ZEOULA, L. M.; WADA, F. Y.; TORII, M. S. Níveis de Suplementação com sal mineral proteinado para novilhos Nelore terminados em pastagem no período de baixa produção forrageira. Revista Brasileira de Zootecnia, Viçosa, MG, v. 33, n. 6, p. 1814-1821, 2004. Suplemento 1.

NATIONAL RESEARCH COUNCIL - NRC. Nutrients requirements of dairy cattle. 7. ed. Washington: National Academy Press, 2001. 381 p.

PAULINO, M. F.; FIGUEIREDO, D. M.; MORAES, E. H. B. K.; PORTO, M. O.; SALES, M. F. L.; ACEDO, T. S.; VILlELA, S. D. J.; VALADARES FILHO, S. C. Suplementação de bovinos em pastagens: uma visão sistêmica. In: SYMPOSIUM OF BEEF CATTLE PRODUCTION, 4., 2004, Viçosa, MG. Anais... Viçosa, MG: Departamento de Zootecnia/UFV, 2004. p. 93-144.

PELL, A. N.; SCHOFIELD, P. Computerized monitoring of gas production to measure forage digestion in vitro. Journal of Dairy Science, Ithaca, v. 76, n. 4, p. 10631073, 1993.

PRADO, I. N.; MOREIRA, F. B.; CECATO, U.; WADA, F. Y.; OLIVEIRA, E.; REGO, F.C.A. Sistemas para crescimento e terminação de bovinos de corte a pasto: avaliação do desempenho animal e características da forragem. Revista Brasileira de Zootecnia, Viçosa, MG, v. 32, n. 4, p. 955-965, 2003.
REIS, R. A.; RUGGIERI, A. C.; CASAGRANDE, D. R.; PÁSCOA, A. G. Suplementação da dieta de bovinos de corte como estratégia de manejo das pastagens. Revista Brasileira de Zootecnia, Viçosa, MG, v. 38, p. 147-159, 2009. Suplemento Especial.

SILVA, F. F.; SÁ, J. F.; SCHIO, A. R.; ÍTAVO, L. C. V.; SILVA, R. R.; MATEUS, R. G. Suplementação a pasto: disponibilidade e qualidade $\mathrm{x}$ níveis de suplementação $\mathrm{x}$ desempenho. Revista Brasileira de Zootecnia, Viçosa, MG, v. 38, p. 371-389, 2009. Suplemento Especial.

SILVA, R. R.; PRADO, I. N.; CARVALHO, G. G. P.; SILVA, F. F.; ALMEIDA, V. V.; SANTANA JÚNIOR, H. A.; PAIXÃO, M. L.; ABREU FILHO, G. Níveis de suplementação na terminação de novilhos Nelore em pastagens: aspectos econômicos. Revista Brasileira de Zootecnia, Viçosa, MG, v. 39, n. 9, p. 2091-2097, 2010.

SNIFFEN, C. J.; O'CONNOR, J. D.; VAN SOEST, P. J.; FOX, D. G.; RUSSEL, J. B. A net carbohydrate and protein system for evaluating cattle diets: II. Carbohydrate and protein availability. Journal Animal Science, Madison, v. 70, n. 11, p. 3562-3577, 1992.

VAN SOEST, P. J. Nutritional ecology of the ruminant. 2. ed. Ithaca: CornelI University Press, 1994. 476 p.

VAN SOEST, P. J.; ROBERTSON, J. B.; LEWIS, B. A. Methods for dietary fiber, neutral detergent fiber, and nonstarch polyssacharides in relation to animal nutrition. Journal of Animal Science, Champaign, v. 74, n. 10, p. 3583-3597. 1991.

ZERVOUDAKIS, J. T.; PAULINO, M. F.; CABRAL, L. S.; DETMANN, E.; VALADARES FILHO, S. C.; MORAES, E. H. B. K. Parâmetros nutricionais de novilhos sob suplementação em sistema de autocontrole de consumo no período de transição águas-seca. Revista Brasileira de Zootecnia, Viçosa, MG, v. 39, n. 12, p. 2753-2762, 2010. 
